\title{
Axiomatic Extension of Risk Measurement
}

\author{
Working Paper · February 2017
}

DOI: $10.13140 /$ RG.2.2.19158.86080

CITATIONS

0

1 author:

Eliza Khemissi

Adam Mickiewicz University

51 PUBLICATIONS 8 CITATIONS

SEE PROFILE
READS

3

Some of the authors of this publication are also working on these related projects: 
Imię i Nazwisko Te dane należy podać dopiero w pliku składanym po recenzji

Afiliacja autora

e-mail: imie.nazwisko@ue.wroc.pl

\section{AXIOMATIC EXTENSION OF RISK MEASUREMENT}

Introduction: In the article the author introduce and prove the additional axiom of measure of risk. She checks, by the method of mathematical proving, which from the well-known functions of risk fulfill this additional axiom. This proofs will be conducted for functions such as: Value at Risk, Expected Shortfall, Median, Absolute Median Deviation, Maximum, Maximum Loss, Half Range, and Arithmetic Average. In other words the purpose of the paper is studying which from the above functions fulfill the additional axiom of measure of risk, which can enrich the Arzner's and other axioms. This axiom is not a consequence of the Arzner's and other axioms. Furthermore the author researches mathematically if mentioned functions of risk retain properties after replacing the stochastic order with partial order. At the end the author presents the new measure of risk which fulfill all the axioms of measure of risk and the additional axiom.

Key words: axioms of risk measure, coherence, VaR, ES,

JEL Classification: C01 


\section{Introduction}

The important step in the process of risk management is risk measuring, which let on the control and monitoring of risk. The importance of this step results from the exposure of the trader on the results of random events. In this article the author will concentrate on well- known and popular in practice and science measures of risk. She will takes into consideration also some new measures of risk. She will check the property of monotonicity of this different risk measures for the new definition of random variable order, which is mathematically partial order. This proofs will be conducted for functions such as: Value at Risk, Expected Shortfall, Median, Absolute Median Deviation, Maximum Loss, Half Range, Maximum, and Arithmetical Average. The purpose of the paper is also studying which from the above functions fulfill the additional axiom of measure of risk, which can enrich the Artzner's and other axioms. This survey unable enlargement of risk measurement theory, and its new application.

\section{Methods}

At the beginning the author will present the definition of measure of risk

\section{Definition (Risk Measure)}

Measure of risk is a function which maps the elements of some linear subspace $V$ of some random variables space on $(\Omega, F, P)$, which contains the constants in real variables space.

$$
\rho: V \rightarrow R,
$$

It fulfills the following axioms

1) monotonicity

$$
\text { for every } X, Y \in V \text {, if } X \leq Y \text { then, } \rho(X) \leq \rho(Y) \text {. }
$$

It means that if the portfolio $X$ generates losses with a smaller probability then the risk joined with this portfolio is smaller.

2) invariance: For every $a \in R$ and for every $X \in V$ 


$$
\rho(X+a)=\rho(X)+a .
$$

This axiom may be interpreted such that when we add some money to the portfolio with value the risk joined with this portfolio is rising, because we may invest more money and lost more. As the values of risk measures are real we can compare them and order them if they fulfill the above axioms [Arzner and others, 1997].

\section{Def.(Coherent measure)}

The measure of risk is coherent if it fulfill the conditions:

3) Positive homogeneousness

For every $\lambda \geq 0$ and for every $\quad X \in V$ the truth is that

$$
\rho(\lambda X)=\lambda \rho(X) .
$$

This axiom may denote that multiplying the quantity of investment causes the risk increases proportionally. The example may be the leverage effect in stock market investing.

4) subadditivity

For every $X, Y \in Y$ there exists the relation:

$$
\rho(X+Y) \leq \rho(X)+\rho(Y) .
$$

In well diversified portfolio the total risk of a loss value is not bigger than the risk of its individual loss values. The rules of coherence let on the consequence in risk assessment. [Artzner and others, 1997] , [Uniejewski, 2004]. We will sum up the information about risk measures researched in this article. The Value of Risk is the biggest value that can be lost as a result of investing in portfolio with a given time horizon and with a given tolerance level [Best, 2000]. VaR is defined as a loss which can't be overran or achieved. It is very popular and universal. It is used by 
banks, investment funds, pension funds, investment homes... There exists some modifications of this measure. There are RiskMetrics, CFaR, EaR. There exists two alternative models of VaR. Jajuga [Jajuga, 2000] defined VaR as a special quantile

$$
P\left(W>W_{0}-V a R\right)=1-\alpha
$$

$W$ - a market value at the end of the considering period, $W_{0}$ - a market value in a given moment $\alpha$ - a tolerance level. In this article we will connect to another written definition of VaR

$$
\inf \{x \in R: F(x) \geq \alpha\}
$$

On the base of VaR Expected Shortfall was created, which is also named the conditional value of risk, and denoted as CVaR or TVAR. ES assess the value of risk in classical way focusing on external results. It is clear that the expected loss on the portfolio may be equal or higher than some qaintile. Usually one assumes to the calculations of ES - 5\% level of confidence. Formally Expected Shortfall may be defined as follow:

$$
E S_{\alpha}=\frac{1}{\alpha} \int_{0}^{\alpha} \operatorname{VaR} R_{\gamma}(X) d \gamma
$$

and in a discrete case as follow:

$$
E S_{\alpha}=-\frac{1}{\alpha}\left(E\left[X 1_{\left\{X \leq x_{\alpha}\right\}}+x_{\alpha}\left(\alpha-P\left[X \leq x_{\alpha}\right]\right)\right]\right) .
$$

Expected Shortfall [see Trzpiot G., 2004 i Acerbi C., Tasche D., 2002], may be interpreted as the mean of the worst $(1-\alpha) \%$ losses on condition that this losses are bigger then value of risk. Other considered in this article measures are plain and doesn't demand commentary, such us $M L$, Maximum, Median, Median Absolute Deviation in continuous and discrete case. In this article we will take into consideration two alternative definitions of random variables. 


\section{Definition (Standard definition of stochastic order of $\mathbf{n}$ degree )}

If the variable $X$ dominates stochastically the variable $Y$, what can be written $X \leq Y$, then

For $\mathrm{n}=0$

$$
\begin{gathered}
F_{y}(y) \leq F_{x}(x) \\
\int_{-\infty}^{y} F_{y}{ }^{n-1}(t) d t \leq \int_{-\infty}^{x} F_{x}{ }^{n-1}(t) d t .
\end{gathered}
$$

It means that with variable $\mathrm{Y}$ is joined bigger risk then the risk with the variable $\mathrm{X}$. As some measures of risk don't include probability we can define the order relations without considering probability.

Weak order partial order is the relation reflexive, transitive and anti-simetric. In this way we will define the relation of the order on stochastic variables.

\section{Definition (Partial order on random variables)}

$$
X \leq Y \Leftrightarrow \underset{x_{i}, y_{i}}{\forall} x_{i} \leq y_{i} .
$$

In the paper the author will analyze mathematically which from the functions of measure are monotonic with this definition of order on random variables. The author will check which from the risk measures fulfill the additional axiom from the paper not published yet of the author. X and $\mathrm{Y}$ are risk variables. They may have two different interpretations as the value of the portfolio and also the value of its part. The axiom is the following:

\section{Axiom}


From any risk variables named $X$ and $Y$

$$
X \leq Y \Rightarrow \mu(Y / X)=\mu(Y)-\mu(X)
$$

This axiom may be interpreter that if the portfolio variable $\mathrm{X}$ is smaller than bigger portfolio variable $\mathrm{Y}$ then the risk joined in the variable $\mathrm{Y}$ after removing the variable $\mathrm{X}$ is equal the risk of $\mathrm{Y}$ minus the risk of $\mathrm{X}$. The author claims that the above axiom is not an obvious consequence of axioms of risk measure and coherence. It is a modification of the one of the basic characteristics of measure resulting from the axioms of mathematical measure. The author will check which from the functions of risk fulfill the additional axiom. Thanks to this new axiom is possible to accurately calculate the risk of a difference of two random variables. This axiom is stronger than the axiom of subbaditivity and is not an obvious consequence of the axioms of subbaditivity and homogeneousness. The risk of difference may be helpful when we reduce the portfolio. For example a bank or an insurance company in the portfolio of loans or insurance policies eliminates the risk through securitization or reinsurance. These companies are interested in risk assessment of the investment portfolio after such reduction.

This axiom has one meaning. The left side may be only partial order. For stochastic order the author suggests the following axiom

$$
Y \leq X \Rightarrow \mu(Y / X)=\mu(Y)-\mu(X)
$$

If the probability of crossing the loss limit is higher for portfolio variables $\mathrm{Y}$ then for variables $X$, then the risk of the portfolio after reduction should be calculated as risk $\mathrm{Y}$ minus risk of $\mathrm{X}$.

In the counterexamples bellow she will use the following formula for probability of a difference:

$$
P(X-Y)=P(X)-P(X \cap Y) .
$$

\section{Mathematical proofs}

At first the author analyze the most popular function of risk.

$$
V a R=\inf \{x: F(x) \geq \alpha\}
$$


7

Counterexample

Let's define the probability distribution of random variable. Suppose that $X \leq Y$

Table 1. The distribution of random variable

\begin{tabular}{|l|l|l|l|l|l|}
\hline$y_{i}$ & $\mathbf{4}$ & $\mathbf{7}$ & $x_{i}$ & 2 & 3 \\
\hline$p_{y_{i}}$ & $\mathbf{1} / \mathbf{2}$ & $\mathbf{1 / 2}$ & $p_{x i}$ & $1 / 2$ & $1 / 2$ \\
\hline$y_{i}-x_{j}$ & 1 & 2 & 4 & 5 & \\
\hline$p_{i j}$ & $1 / 4$ & $1 / 4$ & $1 / 4$ & $1 / 4$ & \\
\hline
\end{tabular}

Source: Own example

$\mu(Y / X)=\inf \left\{y_{i}-x_{j}: F\left(y_{i}-x_{j}\right) \geq 0,5\right\}=4$

$\inf \left\{y_{i}: F\left(y_{i}\right) \geq 0,5\right\}-\inf \left\{x_{i}: F\left(x_{i}\right) \geq 0,5\right\}=4-2=2$.

So $\rho(Y / X) \neq \rho(Y)-\rho(X)$.

For second the author considers expected value

- Expected Value

Counterexample

We notice that $X \leq Y$ 


$$
\sum_{i=1}^{n}\left(x_{i}-y_{j}\right) p_{i j}=\sum_{i=1}^{n} x_{i} p_{i j}-\sum_{i=1}^{n} y_{j} p_{i j}, \rho(Y / X)=\rho(Y)-\rho(X) .
$$

So the expected value fulfill the additional axiom.

- Absolute Median Deviation

Counterexample

Table 3. The distribution of random variable

\begin{tabular}{|l|l|l|l|l|l|}
\hline$y_{i}$ & $\mathbf{4}$ & $\mathbf{5}$ & $x_{i}$ & 2 & 3 \\
\hline$p_{y_{i}}$ & $\mathbf{1} / \mathbf{2}$ & $\mathbf{1} / \mathbf{2}$ & $p_{x_{i}}$ & $1 / 2$ & $1 / 2$ \\
\hline$y_{i}-x_{i}$ & 1 & 2 & 3 \\
\hline$p_{i}$ & & $1 / 4$ & $2 / 4$ & $1 / 4$ \\
\hline
\end{tabular}

Source: Own example

$$
\begin{aligned}
& \operatorname{Med}(|Y-X-\operatorname{Med}(Y-X)|)=\operatorname{Med}(|\{5-3,5-2,4-3,4-2\}-2|) \\
& =\operatorname{Med}(|\{1,2,3\}-2|)=0,5 \\
& \operatorname{Med}(Y-\operatorname{Med}(Y))=\operatorname{Med}|\{5,4\}-4,5|=\operatorname{Med}(\{|0,5,-0,5|\})=0,5 \\
& \operatorname{Med}(X-\operatorname{Med}(X))=\operatorname{Med}(|\{2,3\}-2,5|)=0,5 \\
& 0,5>0 \Rightarrow \rho(Y / X) \neq \rho(Y)-\rho(X) .
\end{aligned}
$$

In the paper titled "About the fundamentals of measures of risk" the author proved that Median is a coherent measure of risk, when we define a sum of random variables in a particular way. That's way it is present in this survey.

- Median

Counterexample 
Table 4. The distribution of random variable

\begin{tabular}{|l|l|l|l|l|l|l|l|}
\hline$y_{i}$ & $\mathbf{4}$ & $\mathbf{6}$ & $x_{i}$ & 2 & 3 & 3,5 \\
\hline$p_{y_{i}}$ & $\mathbf{1} / \mathbf{2}$ & \multicolumn{2}{|l|}{$\mathbf{1} / \mathbf{2}$} & $p_{x_{i}}$ & $1 / 3$ & $1 / 3$ & $1 / 3$ \\
\hline$y_{i}-x_{j}$ & & 0,5 & 1 & 2 & 2,5 & 3 & 4 \\
\hline
\end{tabular}

Source: Own example

$$
\begin{aligned}
& \operatorname{Med}(Y-X)=2,25 \operatorname{Med}(Y)=5 \operatorname{Med}(X)=3 . \text { So } \\
& \rho(Y / X) \neq \rho(Y)-\rho(X) .
\end{aligned}
$$

The median doesn't fulfill the additional axiom.

- Maximum

\section{Counterexample}

Table 5. The distribution of random variable

\begin{tabular}{|l|l|l|l|l|l|}
\hline$y_{i}$ & $\mathbf{4}$ & $\mathbf{5}$ & $x_{i}$ & 2 & 3 \\
\hline$p_{y_{i}}$ & $\mathbf{1} / \mathbf{2}$ & $\mathbf{1} / \mathbf{2}$ & $p_{x_{i}}$ & $1 / 2$ & $1 / 2$ \\
\hline
\end{tabular}

Source: Own example

$$
\begin{aligned}
& \max (5-3,5-2,4-3,4-2)=\max (1,2,3)=3 \\
& \max (5,4)=5, \max (3,2)=3 \\
& 5-3=2 \Rightarrow \rho(Y / X) \neq \rho(Y)-\rho(X) .
\end{aligned}
$$


We will analyze ML as a well- known measure of risk, presented for example in the paper of Czerniak from 2003.

- $M L=\max _{i} p_{i} x_{i}$

Counterexample *

Table 6. The distribution of random variable

\begin{tabular}{|l|l|l|l|l|l|}
\hline$y_{i}$ & $\mathbf{4}$ & $\mathbf{7}$ & $x_{i}$ & 2 & 3 \\
\hline$p_{y_{i}}$ & $\mathbf{1} / \mathbf{2}$ & $\mathbf{1 / 2}$ & $p_{x_{i}}$ & $1 / 2$ & $1 / 2$ \\
\hline$y_{i}-x_{j}$ & 1 & 2 & 4 & 5 \\
\hline$p_{i j}$ & $1 / 4$ & $1 / 4$ & $1 / 4$ & $1 / 4$ \\
\hline
\end{tabular}

Source: Own example

$\rho(Y-X)=\max _{i_{j}} p_{i_{j}}\left(y_{i}-x_{j}\right)=\frac{5}{4}$.

$\rho(Y)-\rho(X)=\max _{i} p_{y_{i}} y_{i}-\max p_{x_{j}} x_{j}=\frac{7}{2}-\frac{3}{2}=2$.

So $\rho(Y-X) \neq \rho(Y)-\rho(X)$

Alternatively from the condition of independence of random variables:

$\rho(Y-X)=\max _{i j} p_{i j}\left(y_{i}-x_{j}\right)=\max _{i j} p_{i} p_{j}\left(y_{i}-x_{j}\right)=\max _{i j}\left(p_{i} p_{j} y_{i}-p_{i} p_{j} x_{j}\right) \leq$ $\max _{i j}\left(p_{i} y_{i}-p_{j} x_{j}\right)=\max _{i} p_{i} y_{i}-\max p_{j} x_{j}=\rho(Y)-\rho(X)$.

- Half Range

Counterexample . Let's take into account the counterexample * 


\section{1}

$$
\rho(Y-X)=0,5(5-1)=2, \quad \rho(Y)-\rho(X)=0,5(7-4)-0,5(3-2)=\frac{3}{2}-\frac{1}{2}=1 .
$$

So

$\rho(Y-X) \neq \rho(Y)-\rho(X)$.

At the end the author will check which of the above functions of risk are still monotonic after changing stochastic order on partial order

- $\operatorname{VaR}=\inf \{x: F(x) \geq \alpha\}$

Let's assume that $X \leq Y \Rightarrow \underset{x}{\forall} x_{i} \leq y_{i}$

So

$\inf \{x: F(x) \geq \alpha\} \leq \inf \{y: F(y) \geq \alpha\} \Rightarrow \rho(X) \leq \rho(Y)$.

- Expected Value

Let's assume that $X \leq Y \Rightarrow \underset{x}{\forall x_{i} \leq y_{i}}$.

Counterexample

Table 7. The distribution of random variable

\begin{tabular}{|l|l|l|l|l|l|l|l|}
\hline$x_{i}$ & $\mathbf{1}$ & $\mathbf{2}$ & $\mathbf{3}$ & $y_{i}$ & 1 & 4 & 4,5 \\
\hline$p_{x_{i}}$ & $\mathbf{1 / 3}$ & $\mathbf{1 / 3}$ & $\mathbf{1 / 3}$ & $p_{y_{i}}$ & 0,8 & 0,1 & 0,1 \\
\hline
\end{tabular}

Source: Own example

$$
\sum_{i} x_{i} p_{x_{i}}=2, \sum_{i} y_{i} p_{y_{i}}=1,65 \Rightarrow \rho(X)>\rho(Y) \text {. }
$$

- Absolute Median Deviation 
Let's assume that

$X \leq Y \Rightarrow \underset{x}{\forall} x_{i} \leq y_{i}$

Counterexample

Table 8. The distribution of random variable

\begin{tabular}{|l|l|l|l|l|l|l|l|}
\hline$y_{i}$ & $\mathbf{1}$ & $\mathbf{1 , 2}$ & $\mathbf{1 , 3}$ & $x_{i}$ & 0 & 0,5 & 1 \\
\hline$p_{y i}$ & $\mathbf{1 / 3}$ & $\mathbf{1 / 3}$ & $\mathbf{1 / 3}$ & $p_{x i}$ & $1 / 3$ & $1 / 3$ & $1 / 3$ \\
\hline
\end{tabular}

Source: Own example

$\operatorname{Med}|X-\operatorname{Med}(X)|=0,5 \quad, \operatorname{Med}|Y-\operatorname{Med}(Y)|=0,1$

So

$\operatorname{Med}|X-\operatorname{Med}(X)|>\operatorname{Med}|Y-\operatorname{Med}(Y)|$ So $\rho(X)>\rho(Y)$.

- $\operatorname{Median}(\mathrm{X})$

$X \leq Y \Rightarrow \hat{i}_{i} x_{i} \leq y_{i} \Rightarrow \operatorname{Med}(X) \leq \operatorname{Med}(Y)$. So $\rho(X) \leq \rho(Y)$.

- Maximum

$X \leq Y \Rightarrow \hat{i}_{i} x_{i} \leq y_{i} \Rightarrow \operatorname{Max}(X) \leq \operatorname{Max}(Y)$. So $\rho(X) \leq \rho(Y)$.

- $M L=\max _{i} p_{i} x_{i}$

Counterexample

$X \leq Y \Rightarrow \wedge_{i}^{\wedge} x_{i} \leq y_{i} \Rightarrow \max _{i} p_{x_{i}} x_{i}=1, \max _{i} p_{y_{i}} y_{i}=0,8$. 


\section{3}

Table 9. The distribution of random variable

\begin{tabular}{|l|l|l|l|l|l|l|l|}
\hline$x_{i}$ & $\mathbf{1}$ & $\mathbf{2}$ & $\mathbf{3}$ & $y_{i}$ & 1 & 4 & 4,5 \\
\hline$p_{x i}$ & $\mathbf{1 / 3}$ & $\mathbf{1 / 3}$ & $\mathbf{1 / 3}$ & $p_{y_{i}}$ & 0,8 & 0,1 & 0,1 \\
\hline
\end{tabular}

Source: Own example

So $\rho(Y)<\rho(X)$.

The author conducts the proof for Half Range which is not a coherent measure of risk.

\section{- Half Range}

\section{Counterexample}

Table 10. The distribution of random variable

\begin{tabular}{|l|l|l|l|l|l|l|l|}
\hline$x_{i}$ & $\mathbf{1}$ & $\mathbf{2}$ & $\mathbf{3}$ & $y_{i}$ & 3 & 4 & 4,5 \\
\hline$p_{x_{i}}$ & $\mathbf{1} / \mathbf{3}$ & $\mathbf{1 / 3}$ & $\mathbf{1 / 3}$ & $p_{y_{i}}$ & 0,8 & 0,1 & 0,1 \\
\hline
\end{tabular}

Source: Own example

$$
X \leq Y \Rightarrow{ }_{i}^{\wedge} x_{i} \leq y_{i} \Rightarrow 0,5\left(X_{\max }-X_{\min }\right)=1, \quad 0,5\left(Y_{\max }-Y_{\min }\right)=0,75
$$
$\rho(Y)<\rho(X)$.

- Arithmetic Average

$$
X \leq Y \Rightarrow \hat{i}_{i} x_{i} \leq y_{i} \Rightarrow \frac{1}{n} \sum_{i} x_{i} \leq \frac{1}{m} \sum_{j} y_{j} \Rightarrow \rho(X) \leq \rho(Y)
$$

The author will prove that Arithmetic Average fulfills axioms of coherent measure of risk and the additional axiom 
- Arithmetic Mean

$\rho(Y-X)=\frac{1}{n m} \sum_{i} \sum_{j}\left(y_{i}-x_{j}\right)=\frac{1}{n} \frac{1}{m} \sum_{i} \sum_{j} y_{i}-\frac{1}{n} \frac{1}{m} \sum_{i} \sum_{j} x_{j}=\frac{1}{n} \sum_{i} y_{i}-\frac{1}{m} \sum_{j} x_{j}=\rho(Y)-\rho(X)$.

The author will prove that the Arithmetic Mean is a coherent measure of risk

$\circ$ monotonicity

$X \leq Y \Rightarrow F_{1}(y) \leq F_{2}(x)$

So

$\frac{1}{n} \sum_{i} x_{i} \leq \frac{1}{n} \sum_{j} y_{j} \Rightarrow \rho(X) \leq \rho(Y)$.

○ homogenousness

From the properties of number series the author conclude:

$\rho(\lambda X)=\frac{1}{n} \sum_{i} \lambda x_{i}=\lambda \frac{1}{n} \sum_{i} x_{i}=\lambda \rho(X)$

○ strong subadditivity

From the properties of number series the author conclude:

$$
\begin{gathered}
\rho(X+Y)=\frac{1}{n} \frac{1}{m} \sum_{i} \sum_{j}\left(y_{i}+x_{j}\right)=\frac{1}{n} \frac{1}{m} \sum_{i} \sum_{j} y_{i}+\frac{1}{n} \frac{1}{m} \sum_{i} \sum_{j} x_{i}=\frac{1}{n} \sum_{i} y_{i}+\frac{1}{m} \sum_{j} x_{i}=\rho(Y)+\rho(X) . \\
\circ \quad \text { invariance }
\end{gathered}
$$

From the properties of number series the author conclude:

$$
\rho(X+a)=\frac{1}{n} \sum_{i=1}^{n}\left(x_{i}+a\right)=\frac{1}{n} \sum_{i=1}^{n} x_{i}+\frac{1}{n} \sum_{i=1}^{n} a=\frac{1}{n} \sum_{i=1}^{n} x_{i}+a=\rho(X)+a
$$


In the survey the author proved that functions of risk such like $\mathrm{VaR}$, , Median Absolute Deviation, Median, Maximum , Maximum Loss and Half Range don't fulfill the additional axiom of measure of risk. When the author takes into consideration the partial order as the order on random variables it occurs that VaR, Median, Maximum and Arithmetic Mean are monotonic and $\mathrm{E}(\mathrm{X})$, Absolute Median Deviation, Maximum Loss and Half Range are not monotonic. The example of coherent measures of risk which is monotonic with partial order and fulfills the additional axiom also, is the Arithmetic Average. Unfortunately it doesn't include probability.

\section{Literature}

Acerbi C., Tasche D., , On the coherence of expected shortfall, Journal of Bank ing \& Finance, 2002 July : 26 (7): 1487-1503.

Buszkowska E, O fundamentach pomiaru ryzyka, Zaszyty Naukowe Uniwersytetu Szczecićskie go, Finanse, Rynki Finansowe, Ubezpieczenia, 2015, nr 73, pp. 373-384

Aparna, Gupta, Risk Management and simulations, CRC PRESS . 2013

Artzner, Ph., F. Delbaen, J.-M. Eber, and D. Heath , Thinking Coherently, RISK 10， 1997 Novem ber: 68-71,

Czerniak T. , Maksymalna strata jako miara ryzyka, Prace naukowe akademii eko nomicznej w Ka towicach. 2003

Jajuga K., 2007, Zarządzanie ryzykiem, Wydawnictwo Naukowe PWN SA, Warszawa,.2004

Uniejewski P, Koherentne miary ryzyka, Wrocław. 2004

http://www.ioz.pwr.wroc.pl/pracownicy/weron/prace/Uniejewski04.pdf. Krawczyk E., , Zastosowa nie modelu ryzyka Value at Risk (VaR) opartego na me todzie Monte Carlo do rynku nieruchomości „EIOGZ”, s 117. 2006

Kubińska E., Markiewicz J. , Pomiar ryzyka jako wyzwanie dla współcze snych finansów, „Oeco nomia", 46(1). 2012,

Kuziak K, Koncepcja wartości zagrożonej VaR (Value at Risk), StatSoft Polska.,2003.

Włodarczyk A. 2011, Koncepcja koherentnych miar ryzyka a ocena ryzyka inwestycyjnego OFE, Prace i Materiały Wydziału Zarządzania Uniwer sytetu Gdańskiego nr 4/5/2011, s. 213-225 